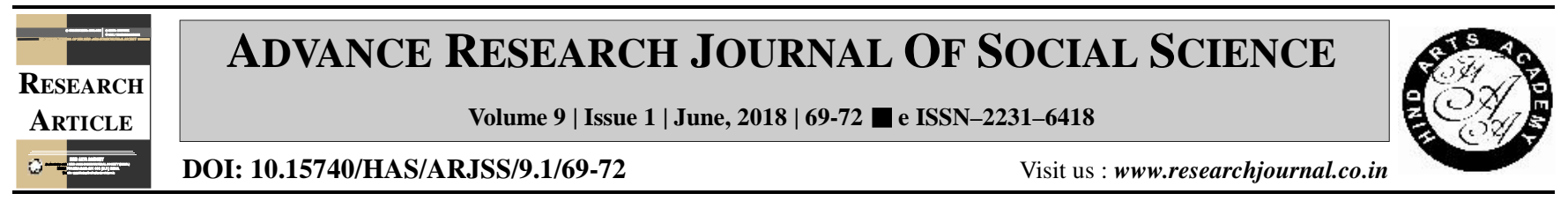

\title{
Disciplinary strategies adopted by parents according to child variables
}

B. Swaroopa Rani* and K. Anuradha

Department of Home Science, S.V. University, Tirupati (A.P.) India

\section{ARTICLE INFO :}

$\begin{array}{lll}\text { Received } & : & 16.02 .2018 \\ \text { Revised } & : & 03.05 .2018 \\ \text { Accepted } & : & 19.05 .2018\end{array}$

\section{KEY WORDS :}

Disciplinary strategies, Pre-school children, Discipline

\section{HOW TO CITE THIS ARTICLE :}

Rani, B. Swaroopa and Anuradha, K. (2018). Disciplinary strategies adopted by parents according to child variables. $A d v$. Res. J. Soc. Sci., 9 (1) : 69-72, DOI: 10.15740/HAS/ARJSS/9.1/69-72.

Copyright@2018 : Hind Agri -

Horticultural Society

*Author for correspondence

\begin{abstract}
Discipline is an organized, regulated and orderly way of life, learning to confirm to the expected patterns of behaviour and customs in an acceptable manner. According to Hoffman's information processing theory (Hoffman, 1977), there are three types of disciplinary strategies- Power-assertive, Love-withdrawal, Inductive.The study sample were mothers of 220 preschool children in Tirupati and Hyderabad towns where three types of pre-schools viz., laboratory nursery schools, anganwadi centers and private schools were available. Mothers were administered with Disciplinary Strategies Adopted by Parents Scale. Results revealed that Majority of the mothers were using less power assertive and more love withdrawal strategies. Disciplinary strategies adopted by mothers did not differ significantly according to gender of the child but mothers differed significantly in the mean scores of power assertive and inductive disciplinary strategies according to age of the child.
\end{abstract}

